\title{
श्रीराम शर्मा आचार्य द्वारा प्रतिपादित विचारक्रान्ति का सम्प्रत्यय, महत्व एवं अनुप्रयोग
}

प्रज्ञा सिंह एवं दीपक सिंह

सारांश

समाज में, परिवार में, मनुष्य जीवन में जो भी समस्याएँ उत्पन्न होती हैं उनका मूल कारण विचारों में गिरावट है; वैचारिक स्तर के निम्न होने पर व्यक्तिगत स्तर पर स्वार्थपरता, महत्वाकांक्षा बढ़ जाती है, पारिवारिक स्तर में छोटी-छोटी बातों में कलह होती है और सामाजिक स्तर पर विकृत परंपराएँ, प्रथाएँ व अपराध बढ़ते हैं और पोषित होते हैं। विचारों का स्तर गिर जाने से नकारात्मकता का सहज रूप से विचार में प्रवेश होता है और फिर तरह-तरह की मानसिक समस्याएँ भी पैदा होती हैं। आज मनुष्य जाति अनेक तरह की समस्याओं से जूझ रही है और नित नई-नई समस्याओं से घिरती चली जा रही है। आचार्य श्री ने इस समस्या से उबरने का एक मात्र उपाय विचार-क्रान्ति को माना है। विचार-क्रान्ति का अर्थ है- मनुष्य के आस्था स्तर को निकृष्टता से मोड़कर उत्कृष्टता की ओर अभिमुख करना। इसके लिए सबसे पहले जरूरी है- जनमानस के परिष्कार को सर्वोपरि प्राथमिकता दी जाए एवं विचार क्रान्ति पर ध्यान केन्द्रिय किया जाय। यदि इस प्रक्रिया में सफलता पाई जा सके तो समझना चाहिए कि अगणित संकटों का समाधान केवल एक ही उपचार से संभव हो गया।

कूट शब्द - विचारक्रान्ति, आस्था-संकट, परिवर्तन, विचार एवं जनमानस।

आज मनुष्य का जीवन सुविधा व साधन सम्पन्न है लेकिन वह आज से 200 वर्ष पूर्व मनुष्य की तुलना में स्वयं को अधिक अभावग्रस्त, रुगण, चिन्तित व एकाकी ही अनुभव कर रहा है। सुख-सन्तोष की दृष्टि से वह पहले की अपेक्षा और अधिक दीन-दुर्बल हो गया है। शारीरिक स्वास्थ्य, मानसिक संतुलन, नैतिक विकास, पारिवारिक सौजन्य, सामाजिक सद्भाव, आर्थिक संतोष व आंतरिक उल्लास की दृष्टि से मनुष्य जाति समग्र विश्व में नई-नई समस्याओं से घिरती चली जा रही है। दुर्मतिजन्य दुर्गति ही चारों ओर दिखाई देती है एवं यह दुर्बुद्धि भावनात्मक स्तर पर एक विचार-क्रान्ति के बिना ठीक होना संभव नहीं है ऐसा आचार्य श्री का अभिमत हैं।

\section{वर्तमान की स्थिति}

वर्तमान समय में मनुष्य जाति की व्यक्तिगत एवं सामाजिक कठिनाईयों का कारण उसकी विचारणाओं का स्तर गिर जाना ही हैं। विचार स्तर गिरने से ही उपजी असंयम की प्रवृत्ति ने मनुष्य के स्वास्थ्य का बुरी तरह क्षरण किया है। स्वार्थ, संकीर्णता एवं अनुदारिता की प्रवृत्ति के कारण व्यक्ति अपने पारिवारिक स्नेह-सौहार्द्र से वंछित होता जा रहा है और इसके कारण परिवार विसंगठित हो रहे हैं। निम्न मानसिकता से उत्पन्न अपराधी मनोवृत्ति ने समाज में असुरता एवं अशान्ति का साम्राज्य फैलाया है। व्यक्तिगत स्तर पर उत्पन्न आत्महीनता ने मनुष्य की प्रगति को ही अवरुद्ध कर दिया है। इससे उत्पन्न अहंकार एवं अविनयशीलता से मनुष्य विरोध, असहयोग, तिरस्कार एवं
दूसरों से शत्रुता निभा रहा है। जीवन में व्याप्त असन्तुलन ने उसकी मानसिक शक्ति का बहुत ह्रास किया है। व्यक्ति को जिन समस्याओं का सामना करना पड़ रहा है, उसका मुख्य कारण निम्न-संकीर्ण विचारधारा का होना है, जिसके परिणाम स्वरूप आज मनुष्य जाति आस्था संकट के गंभीर दौर से गुजर रही है।

आस्था संकट का अर्थ है आदर्शों के प्रति श्रद्धा गँवाना (आचार्य, 1988, पृ. 48)। आदर्श जीवन के पथ प्रर्दशक होते है। जिनके मार्ग दर्शन में ही समस्त आत्मिक, परिवारिक, समाजिक व राष्ट्रिय विकास निर्भर करता है। वास्तव में आदर्श कोई व्यक्ति नहीं बल्कि श्रेष्ठ विचार होते है। वर्तमान समय में श्रेष्ठ आदर्शो का स्थान व्यक्ति की संर्कीण मानसिकता, स्वार्थ बुद्धि व अहंकार ने ले लिया है जिसके कारण व्यक्ति को किसी पर विश्वास नहीं रह गया है और इसी वजह से उसमें बुद्धि-विभ्रम पैदा हो गया है। ऐसी स्थिति में मनुष्य का कौशल एवं वैभव बढ़ा हुआ होने पर भी निम्न मानसिकता के कारण तात्कालिक लाभ के प्रलोभन में अपनी क्षमता को विनाशकारी संरचनाओं में लगा रहा है।

आज समाज के सामने जो भी समस्याएँ हैं- वे सभी दुष्प्रवृत्तियों द्वारा उत्पन्न की गयी हैं। आलस्य, संकीर्णता, स्वार्थपरता, सामूहिकता का अभाव, नागरिक कर्त्तव्यों की उपेक्षा, भीरुता जैसे सामाजिक दोष-दुर्गुणों ने आज खाद्यान्न, मँहगाई, बेकारी व बेरोजगारी, गरीबी, अशिक्षा व अपराधिक समस्याएँ उत्पन्न की हैं (ब्रह्मवर्चस, 1998a, पृ. 1.5)। युद्धोन्माद, साम्राज्यवाद, पूँजीवाद, जातिभेद, लिंगभेद, 
आर्थिक विषमता, अभावग्रस्तता, बेकारी, बेरोजगारी, बीमारी आदि समस्याएँ समाज की प्रगति को अवरुद्ध किए हुए हैं।

\section{क्रान्ति का अर्थ एवं सिद्धान्त}

क्रांति का अर्थ है- वैचारिक परिवर्तन की एक ऐसी प्रक्रिया जिसमें जनचेतना अनौचित्य का विरोध करने, छोड़ने तथा औचित्य को अपनाने के लिए विवश हो जाय। जिसमें व्यक्ति के अंतरंग और बहिरंग का आमूलचूल परिवर्तन हो। एक ऐसा परिवर्तन जो मनुष्य समुदाय को परस्पर एक-दूसरे के निकट लाता तथा बाँधता हो। समाज की रूढ़िग्रस्त परम्पराओं और कुरीतियों को समाप्त करता तथा स्वस्थ परम्पराओं के प्रचलन के लिए साहस दिखाता हो (ब्रहमवर्चस, 1998a, पृ. 1.45)। इस तरह की क्रान्ति हिंसात्मक तरीके से नहीं बल्कि विचारक्रान्ति के अहिंसात्मक आध्यात्मिक प्रयोग-उपचारों के द्वारा ही संभव है। इतिहास में इस तरह की क्रांति के भी अनेक उदाहरण हैं। जैसे बुद्ध का धर्म-चक्र प्रवर्तन इसी तरह की क्रांति का आदर्श समग्र स्वरूप था। गान्धी जी का स्वराज्य आन्दोलन भी इन्हीं आदर्शों से अभिप्रेरित था।

विश्व में अनेक हिंसात्मक क्रांतियाँ हुई हैं, इनसे सत्ता में परिवर्तन भी हुए हैं लेकिन इन क्रान्तियों के बावजूद मानव जाति की मूल समस्या अपने स्थान पर यथावत् रही है। फ्रांस, इंग्लेण्ड, अमेरिका, रोम तथा रूस की प्रख्यात् क्रान्तियों के बावजूद यह नहीं कहा जा सकता है कि इन देशों में मानवतावाद व्यवस्था स्थापित हो गयी है। सही मायने में परिवर्तन व क्रान्ति लाने के लिए एक ऐसे सशक्त वैचारिक वातावरण के सृजन की आवश्यकता होती है, जिससे मनष्य उस परिवेश की उत्कृष्टता में ढलता चला जाय।

देश-विदेशों में हुई क्रान्तियों का मूल आधार विचार-क्रान्ति ही रहा है। इसके अन्तर्गत दो सिद्धान्त काम करते दिखाई देते हैं। एक है- सातत्य का सिद्धान्त और दूसरा परिवर्तन का । ये दोनों सिद्धान्त परस्पर विरोधी लगते हैं, परन्तु ये विरोधी हैं नहीं। सातत्य के भीतर परिवर्तन की झलक है। इसी प्रकार परिवर्तन भी अपने अन्दर सातत्य का कुछ अंश छिपाए रखता है। असल में व्यक्ति का ध्यान उन्हीं परिवर्तनों की ओर जाता है, जो क्रान्ति के रूप में अचानक फट पड़ते हैं। फिर भी प्रत्येक भूगर्भ शास्त्री जानता है कि धरती की सतह पर जो बड़े-बड़े परिवर्तन होते हैं, उनकी चाल बहुत धीमी होती है। इसी तरह क्रान्तियाँ भी धीरे-धीरे होने वाले परिवर्तन और रूपान्तरण की एक बहुत लम्बी प्रक्रिया का बाहरी प्रमाण बस होती हैं (शर्मा, 1990, पृ. 41, 42)।
जनविकलता की तड़प ही क्रांति की उपज है। क्रान्ति की संरचना और प्रक्रिया पर गौर करने पर स्पष्ट होता है कि इसका आरम्भ हमेशा कुछ विचारशील, साहसी, परम्पराओं की तुलना में विवेक को महत्व देने वाले व्यक्तियों के द्वारा होता है।

\section{विचार-क्रान्ति अभियान की शुरुआत एवं उसका अर्थ}

मनुष्य के वैचारिक स्तर को ऊपर उठाने के लिए पं. श्रीराम शर्मा आचार्य ने विचार-क्रान्ति का अभियान शुरूआत सन् 1967 से की थी। इसके पहले भी उन्होंने विचार की शक्ति के सन्दर्भ में अखण्ड ज्योति पत्रिका में कई महत्वपूर्ण लेख लिखे। लेकिन इस दिशा में विधिवत शुरुआत मार्च 1967 में लेख- 'विचार-क्रान्ति आज की सबसे बड़ी आवश्यकता' के साथ किया (आचार्य, 1967a, पृ. 7)। विचार-क्रान्ति का अर्थ है- मनुष्य के आस्था स्तर को निकृष्टता से मोड़कर उत्कृष्टता की ओर अभिमुख करना है (ब्रह्मवर्चस, 1998a, पृ. 1.6)। इस 'विचार-क्रान्ति अभियान' को आचार्य श्री ने इस समय की सबसे बड़ी आवश्यकता एवं सशक्त महाक्रान्ति कहा है। सभी ऐतिहासिक उदाहरणों और राष्ट्रीय सामाजिक प्रगति के मूल में विचारक्रान्ति का ही आधारभूत योगदान रहा है, और वही व्यक्ति इसका माध्यम बने है जिन्होंने अपने निजी स्वार्थों की उपेक्षा की।

आज का युग विचारों का है। जो विचार प्रबल होंगे वे ही अपने अनुकूल-अनुरूप परिस्थितियाँ उत्पन्न कर लेंगे (आचार्य, 1967a, पृ. 8)। इस समय संसार की सबसे बड़ी शक्ति शस्त्र नहीं वरन् विचार है। दुनिया के कई देशों में अब प्रजातांत्रिक शासन है। अब चूँकि चयन व निर्णय शक्ति जनता के हाथों में है इसलिए जिस दिशा में जन-मानस का प्रवाह बहता है, उसी तरह की परिस्थितियाँ बन जाती हैं। इस जन-प्रवाह को शस्त्रों से नहीं, विचारों से ही रोका जा सकता है। इसलिए युग परिवर्तन का एक अर्थ है- विचार परिवर्तन (ब्रहमवर्चस, 1998b, पृ. 2.1)। यदि जन साधारण की वर्तमान मान्यताओं एवं आस्थाओं का स्तर बदला जा सके, तो हाड़-माँस की दृष्टि से समान होने पर भी मनुष्य आश्चर्यजनक रीति से बदल जाएगा ।

\section{विचार क्रान्ति अभियान की आवश्यकता}

आज समाज की जो भी स्थिति है, उसमें सुधार की जरूरत है। समाज में जो भी नीति-नियम, परंपराएँ निभायी जा रही हैं, समय के साथ उसमें विकृतियाँ पनप जाती हैं। इसलिए यह आवश्यक हो गया है कि समय के अनुरूप नीति-नियमों, परंपराओं में सुधार लाया जाए, उसमें 
आवश्यक फेर-बदल किया जाए। किन्तु ऐसा कर पाना सरल होता है क्योंकि जिस मनःस्थिति में लोग इतने वर्षों से जी रहे होते हैं, उसमें जरा-सा भी परिवर्तन की बात करने पर विद्रोह उभरता है। इस वास्तविकता को समझने और समस्याओं का चिरस्थायी उपाय-उपचार सोचने के लिए उस तह तक जाना और उस उद्गम को खोजना जरूरी है जिसके कारण ये परिस्थितियाँ निर्मित हुई हैं।

यह उद्गम और कुछ नहीं बल्कि व्यापक और बलिष्ठ बनी हुई मनुष्य की दुर्बुद्धि है, जो इन दिनों चारों ओर अपना विस्तार एवं अधिकार किए हुए है । इसी से जनमानस को जूझना पड़ेगा और इसे घटाना, हटाना और मिटाना होगा। मूर्धन्यों को इसी के विरुद्ध धर्म युद्ध छेड़ना होगा। लोकमानस के परिष्कार को 'युग धर्म' मानना होगा और उन अस्त्र-शस्त्रों को खोजना होगा, जो अनौचित्य को उखाड़कर उसके स्थान पर मानवी गरिमा के विचारशीलता को प्रतिष्ठापित कर सकें, यही है वह विचार क्रान्ति अभियान, जिसे समय की सबसे बड़ी आवश्यकता कहा जा सकता है (आचार्य, 1988, पृ. 48)।

इतिहास में जब भी कोई बड़े परिवर्तन हुए हैं, वैचारिक स्तर पर ही हुए हैं और आज भी ऐसे ही सशक्त व ओजस्वी विचारों की जरूरत है जिन्हें समझने, मानने व अपनाने के लिए लोग सहज ही तैयार हो जाए। आज समाज में जो पाप, अनाचार, दंभ, छल, सत्य, शोषण आदि दोषों का बाहुल्य होने से भारी अव्यवस्था उत्पन्न हो रही है, उसके लिए किन्हीं अमुक व्यक्तियों को दोषी ठहराने या उन्हें मार-काट देने से समस्या का हल नहीं हो सकता। विचार-परिवर्तन ही एकमात्र वह आधार रह है, जिसके माध्यम से विभिन्न प्रकार के कष्टों का सृजन करने वाले दुर्गुणों को निरस्त किया जा सकता है और न्याय तथा शांति की स्थापना की जा सकती है (आचार्य, 1967a, पृ. 8)। जब समाज में अच्छे विचारों, आदर्शवादी सिद्धान्तों की लहरें उफान लेंगी और लोग इसका स्वागत करेंगे, तभी विचार-क्रांति अभियान का उद्देश्य सफल हो सकेगा।

आज चारों ओर शारीरिक, बौद्धिक, आर्थिक, सामाजिक और राष्ट्रीय क्षेत्रों में अनेक प्रकार की समस्याएँ और उलझने हैं। इन सबका एक ही हल है- आन्तरिक संकीर्णता और दुर्बलता को मिटाना। ऐसा तभी करना संभव है जब विचारों में क्रान्तिकारी परिवर्तन आए (आचार्य, 1963b, पृ. 39)। चूँकि विचार क्रांति ही समस्त क्रान्तियों की जननी है। इसलिए वैचारिक स्तर में परिवर्तन होते ही बाहरी सभी परिस्थितियाँ स्वयमेव बदलने लगती हैं।

\section{विचार-क्रान्ति का महत्व}

जीवन का विकास मनोसामाजिक होता है। अस्थायी क्रान्ति का स्थाई समाधान एक ही है-व्यक्ति बदले, समाज सुधरे। आज की आधुनिक परिस्थिति में मनुष्य जीवन की विपन्न स्थिति देखकर यही लगता है कि घूम फिर कर मनुष्य वहीं बल्कि उससे भी बदतर हालत में आ पहुँचा है जहाँ से उसने अपनी यात्रा शुरू की थी। अब उसे पुनः आवश्यकता पड़ गयी है कि नयी व्यवस्था का सृजन हो। परस्पर के सम्बन्ध नए सिरे से विकसित हों अर्थात् समाज नीति की नयी र्मृति बने। विनिमय प्रणाली ऐसी हो जिससे हर किसी की सामान्य जरूरतें पूरी हो सकें। मानवी चेतना के अवरोहण, बहिरंग जीवन को परिष्कृत करने वाली ऐसी प्रक्रिया विकसित हो, जिसके निकट अंधविश्वास आ ही न सके। इसके लिए क्रांति का नया आयाम- विचार क्रान्ति ही है (शर्मा, 1990, पृ. 43)।

विचारक्रांति का केन्द्र व्यक्ति है और उसकी परिधि है समाज। इसी क्रान्ति के माध्यम से सद्भाव, सहनशीलता, सदाशयता मनुष्य के अन्तर पैदा होती है। तलवार से मनुष्य को पराजित किया जा सकता है, जीता नहीं जा सकता। मनुष्य को जीतना, उसके हृदय पर अधिकार पाना है और हृदय की राह समर भूमि की लाल-कीच नहीं, सहिष्णुता का शीतल प्रदेश है, उदारता का उज्जवल क्षीर समुद्र है। विचारों की क्रान्ति व्यक्ति के अन्दर यही राह प्रशस्त करती है। टूटे दिलों को जोड़ती है और पुराने घावों को सहला कर उन्हें भरती जाती है।

\section{विचार-क्रान्ति द्वारा समस्याओं का समाधान}

आज व्यक्ति और समाज के सम्मुख अगणित समस्याएँ है। विडंबना यह है कि समय के साथ नयी-नयी समस्याएँ उत्पन्न हो रही है जिसका समाधान सबसे जरूरी है। यदि समय रहते इन समस्याओं का समाधान नहीं किया गया तो अनर्थकारी परिणाम समाने आयेगे। यदि इन सभी समस्याओं का गंभीरता से विश्लेषण किया जाये तो यह स्पष्ट होता है कि समस्याओं के रूप भले ही भिन्न-भिन्न हों किन्तु इन सभी के मूल में एक ही कारण व्याप्त है- वह है विकृत मानसिकता।

आचार्य श्री ने इन समस्त समस्याओं का एक ही समाधान- विचार क्रान्ति बताया है। विचार-क्रान्ति ही वह माध्यम है जिसके आधार पर जन-मानस की मान्यताओं एवं निष्ठाओं में हेर-फेर करके गतिविधियों एवं क्रिया-पद्धतियों को बदला जा सकता है (आचार्य, 1967a, पृ. 9)। आचार्य श्री के अनुसार विचार-क्रान्ति के माध्यम से ही नैतिक, बौद्धिक एवं सामाजिक क्षेत्र में घुसी हुई अवांछनीयता को दूर किया 
जा सकता है और यह कार्य जिस गति से होगा, उसी गति से परिस्थिति भी बदलेगी (आचार्य, 1988, पृ. 48)।

वैचारिक विकृतियाँ अच्छे-भले जीवन क्रम को नारकीय बना देती हैं- काम, क्रोध, लोभ, मद, मत्सर, अहंकार आदि विकृतियों से ग्रसित मनुष्य अकारण ही अपने लिए विपत्तियों को आमन्त्रित करता है। यदि मनुष्य अपनी विचार-पद्धति पर नियन्त्रण कर ले तो उसकी शक्ति, प्रगति, समृद्धि निश्चित ही होगी।

\section{विचार क्रान्ति की भावी संभाव्यता}

आचार्य ने अपनी महत्वपूर्ण पत्रिका अखण्ड ज्योति में भविष्य में होने वाले परिवर्तनों के प्रकार एवं उसकी झलक झांकी की चर्चा की है। उनका कहना है कि- 'अगले कुछ ही दिनों में एक महानतम सर्वांगीण सार्वभौम आन्दोलन एक प्रचण्ड दावानल की तरह प्रकट होने वाला है। उसके अनेक रूप और अनेक प्रकार होंगे। अनेक नामों से, अनेक संस्थानों-संगठनों के द्वारा अनेक रूपों में अनेक व्यक्तियों द्वारा यह चलेगा। धर्म-क्षेत्र से लेकर अर्थ क्षेत्र, समाज-क्षेत्र, राज्य क्षेत्र तक में एक महानतम विचार क्रांति उत्पन्न होगी। यह विचार-परिवर्तन नये युग का सृजन करेगा। उस प्रयोजन की पूर्ति के लिए अनेक सृजनात्मक प्रवृत्तियाँ चलेंगी और धरती को लाल कर देने वाले अनेक संघर्ष होंगे' (आचार्य, 1967b, पृ. 41)। 'सम्पूर्ण विश्व इन दिनों एक ऐसे संक्रान्ति काल से होकर गुजर रहा है जिसमें परिवर्तन अवश्यम्भावी है। जो सूक्ष्म दृष्टि सम्पन्न हैं वे जानते हैं कि सांस्कृतिक पुनरोदय की ठीक यही घड़ी है। यह सन्ध्या वेला है- जिसमें अवांछनीयता की तमिस्रा छटेगी, प्रज्ञा का आलोक अपनी स्वर्णिम किरणों के साथ फैलेगा। इन दिनों वही हो रहा है जिसका उद्घोष योगीराज अरविन्द ने किया था, जिसकी सम्भावना पाश्चात्य भविष्यविद् करते हैं। सांस्कृतिक पुनरोदय की इस स्वर्णिम आभा को इन दिनों विचार क्रांति के रूप में देखा जा सकता है' (आचार्य, 1981, पृ. 52)।

\section{विचार-क्रान्ति का अनुप्रयोग}

विचार-क्रान्ति के अनुप्रयोग से तात्पर्य है कि वे माध्यम, तकनीकें एवं विधियाँ जिसके द्वारा विचार क्रान्ति का विस्तार किया जा सकता हैं और इससे होने वाले सत्परिणामों का लाभ लिया जा सकता है। इसके लिए व्यक्तिगत स्तर पर हर मनुष्य को अपनी विचारशक्ति को सुदृढ़, समुन्नत व उष्कृष्ट बनाना होगा। उत्कृष्ट स्तर के विचारों का स्वाध्याय, आदर्श व्यक्तियों का सत्संग, मनोभूमि को सशक्त बनाने के हर संभव उपाय करने होगें, इसमें व्यक्ति द्वारा किया गया
चिन्तन, मनन भी शामिल है। कुप्रचलनों, परंपराओं और प्रचलित मान्यताओं के स्थान पर उपयुक्त विवेकपूर्ण मान्यताओं को ही अपनाना होगा और कुप्रचलनों को समाप्त करना होगा। समाज में नयी विधि व्यवस्था को विवेक के आधार पर निर्मित करना होगा और इसके लिए सशक्त एवं विचारसम्पन्न मनोभूमि के व्यक्तियों का संगठित होना बहुत जरूरी है, जो अपने तर्कों से प्रचलित तर्कों को काट सके और नयी व्यवस्था को स्थापित करने के लिए लोगों के विचारों में परिवर्तन कर सकें, इससे होने वाले लाभों से उन्हें अवगत करा सकें। इसके लिए मीडिया, दूरदर्शन, कलामंच, ज्ञानमंच, संगोष्ठियाँ, रैलियाँ आदि विविध तरीकों का सहारा लिया जा सकता है और इसका उद्देश्य केवल इतना होना चाहिए कि व्यक्ति के अंदर जड़ पकड़ चुकी मान्यताएँ बदली जा सके और उसके स्थान पर उपयुक्त समाधान सुझाया जा सके। तभी विचार-क्रान्ति की लहर व्यक्तिगत क्षेत्र से विस्तृत होकर समाज, राष्ट्र एवं विश्व को प्रभावित कर सकेगी।

आचार्य श्री का कहना है कि 'आज हम ऐसे ही क्षणों से गुजर रहे हैं, जब हमें पुराने व प्रतिगामी विचारों को त्याग कर युगानुकूल नूतन विचारधारा को हृदयंगम करना चाहिए, जो स्वयं हमारे लिए और इस युग के लिए कल्याणकारी हो; वास्तविक विचार-क्रांति तभी आ सकती है' (शर्मा, 1991, पृ. 52)।

आज राष्ट्र को सशक्त बनाने के लिए अनेक माध्यम, साधनों और उपकरणों की आवश्यकता है, उसके प्रकार और कार्यक्रम भी अनेक हैं; पर वह सब कुछ जिस आधार पर निर्भर है, वह है भावना। भावना के अभाव में प्रगति की सारी प्रक्रियाएँ निर्जीव और प्रदर्शन मात्र बनी रहती हैं। इसलिए विचार क्रान्ति तभी सही अर्थों में सार्थक व संभव है जब मनुष्य अपनी भावनाओं का परिष्कार करे।

इसलिए आचार्य श्री का कहना है कि 'हमें जनमानस में कर्त्तव्य पालन की, नीति, धर्म और सदाचार की, आस्तिकता और परमार्थ की प्रचण्ड भावनाएँ उत्पन्न करनी चाहिए। तभी लोगों में सही अर्थों में विचार क्रान्ति का आरंभ हो सकेगा' (आचार्य, 1963a, पृ. 43)।

\section{निष्कर्ष}

मनुष्य के वैचारिक स्तर में गिरावट का ही यह परिणाम है कि आधुनिक समय में समाज में तरह-तरह की विकृतियाँ उभर रही हैं और विभिन्न तरह की शारीरिक, मानसिक, सामाजिक, राष्ट्रीय व विश्वव्यापी समस्याएँ उभर रही हैं। इन समस्याओं का एक ही समाधान है कि वैचारिक स्तर में उत्कृष्टता लायी जाएँ। विचारों की दिशा को बदलने वाला 
सिंह एवं सिंह

यह परिवर्तन 'विचार-क्रान्ति' है। वैचारिक स्तर में परिवर्तन व उत्कृष्टता से ही विचार क्रांति संभव हो सकती है।

प्रज्ञा सिंह, पी-एच० डी०; दीपक सिंह, पी-एच० डी०, नेट, असिस्टेन्ट प्रोफेसर, मनोविज्ञान विभाग, देव संस्कृति विश्वविद्यालय, हरिद्वार,(उत्तराखण्ड), भारत।

\section{संदर्भ सूची}

आचार्य, श्रीराम शर्मा (1988, नवम्बर). नवयुग की संभावनाएँ-बुद्धि विपर्यय से विचारक्रान्ति निपटेगी। अखण्ड ज्योति, $11,48$.

ब्रह्मवर्चस (1998a). सामाजिक, नैतिक एवं बौद्धिक क्रान्ति कैसे? (वांगमय, खण्ड 65, द्वितीय संस्करण, पृ० 1.45, 1.5, 1.6)/ मथुराअखण्ड ज्योति संस्थान।

आचार्य, श्रीराम शर्मा (1967a, मार्च). विचार-क्रांति आज की सबसे बड़ी आवश्यकता। अखण्ड ज्योति, $3,7,8,9$
शर्मा, भगवती देवी (1990, अक्तुबर). क्रान्ति का नया आयाम-विचार क्रान्ति। अखण्ड ज्योति, $10,41,42,43$

आचार्य, श्रीराम शर्मा (1963a, फरवरी). इतना तो करना ही होगा। अखण्ड ज्योति, 2,43

आचार्य श्रीराम शर्मा (1967b, मार्च). छोटा किन्तु महान शुभारम्भ। अखण्ड ज्योति, 3,41

ब्रहमवर्चस (1998b). युग निर्माण योजना-दर्शन, स्वरूप व कार्यक्रम (वांगमय, खण्ड 66, द्वितीय संस्करण, पृ० 2.1)/मथुरा- अखण्ड ज्योति संस्थान।

आचार्य, श्रीराम शर्मा (1981, फरवरी). महान परिवर्तन की वेला अति सन्निकट। अखण्ड ज्योति, 2,52

आचार्य, श्रीराम शर्मा (1963b, फरवरी). समस्त समस्याओं का एक ही हल। अखण्ड ज्योति, 2,39

शर्मा, भगवती देवी (1991, मार्च). विचार क्रांति की वेला आ पहुँची। अखण्ड ज्योति, 3,52 